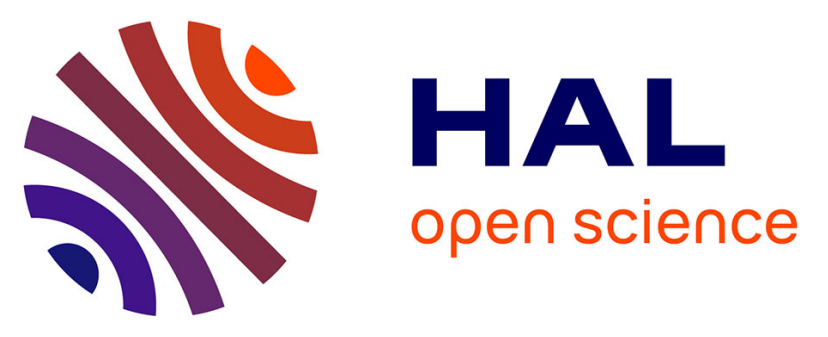

\title{
Made-to-order porous electrodes for supercapacitors: MOFs embedded with redox-active centers as a case study
}

Arijit Mallick, Hanfeng Liang, Osama Shekhah, Jiangtao Jia, Georges Mouchaham, Aleksander Shkurenko, Youssef Belmabkhout, Husam N Alshareef, Mohamed Eddaoudi

\section{To cite this version:}

Arijit Mallick, Hanfeng Liang, Osama Shekhah, Jiangtao Jia, Georges Mouchaham, et al.. Made-toorder porous electrodes for supercapacitors: MOFs embedded with redox-active centers as a case study. Chemical Communications, 2020, 56 (12), pp.1883-1886. 10.1039/C9CC08860A . hal-03090535

\section{HAL Id: hal-03090535 https://hal.science/hal-03090535}

Submitted on 29 Dec 2020

HAL is a multi-disciplinary open access archive for the deposit and dissemination of scientific research documents, whether they are published or not. The documents may come from teaching and research institutions in France or abroad, or from public or private research centers.
L'archive ouverte pluridisciplinaire HAL, est destinée au dépôt et à la diffusion de documents scientifiques de niveau recherche, publiés ou non, émanant des établissements d'enseignement et de recherche français ou étrangers, des laboratoires publics ou privés. 


\title{
Made-to-order porous electrodes for supercapacitors: MOFs embedded with redox-active centers as a case study $\dagger$
}

\author{
Arijit Mallick, ${ }^{a}$ Hanfeng Liang, ${ }^{b}$ Osama Shekhah, ${ }^{a}$ Jiangtao Jia, ${ }^{a}$ Georges Mouchaham, ${ }^{a}$ Aleksander Shkurenko, ${ }^{a}$ Youssef \\ Belmabkhout, ${ }^{\mathrm{a}}$ Husam N. Alshareef ${ }^{* b}$ and Mohamed Eddaoudi*a
}

\begin{abstract}
In this work, a pre-designed Zr-based-MOF encompassing an organic linker with a redox active core is synthesized and its structureproperty relationship as a supercapacitor electrode is investigated. An enhanced performance is revealed by the combination of this MOF's high porosity and redox core incorporation, which alters its double-layer and pseudocapacitance, respectively. An increase in the capacitance performance by a factor of two is achieved via post-synthetic structure rigidification using organic pillars.
\end{abstract}

Energy storage nowadays is considered a key element in most renewable energy systems. Existing technologies, such as wind turbines and solar photovoltaics are intermittent in nature. ${ }^{1,2}$ Thus, energy storage technologies (like batteries and supercapacitors) have the potential to mitigate this intermittency problem via storing the generated energy for later use upon demand. ${ }^{1}$ Supercapacitors are an important storage technology due to their charge storage mechanism, which does not involve irreversible chemical reactions., Therefore, stable porous materials are attractive electrode materials for capacitive energy storage applications due to their high surface areas, and open structures that enhance rapid ion transport. ${ }^{5}$

Commercial supercapacitors use porous carbon that operate at a very high charge/discharge rate and have a long life cycle; however, new applications demand higher capacitances. In contrast, pseudocapacitive materials with redox-active metal centers have higher capacitance, but shorter cycle life. ${ }^{6,7}$ Hence, there is a need for the development of electrodes that combine both redox and electric double layer capacitances (EDLC), which can provide high capacitance and long cycle life. In this context, metal-organic frameworks

\footnotetext{
${ }^{a}$ Functional Materials Design, Discovery and Development Research Group $\left(F M D^{3}\right)$, Advanced Membranes and Porous Materials Center (AMPMC), Division of Physical Sciences and Engineering (PSE), King Abdullah University of Science and Technology (KAUST), Thuwal 23955-6900, Kingdom of Saudi Arabia.

E-mail: mohamed.eddaoudi@kaust.edu.sa

${ }^{b}$ Materials Science and Engineering, Division of Physical Sciences and Engineering (PSE), King Abdullah University of Science and Technology (KAUST), Thuwal 23955-6900, Kingdom of Saudi Arabia. E-mail: husam.alshareef@kaust.edu.sa $\dagger$ Electronic supplementary information (ESI) available. CCDC 1849328. For ESI and crystallographic data in CIF or other electronic format see DOI: 10.1039/c9cc08860a
}

(MOFs), a new class of porous materials, are promising candidates as electrodes due to their unique properties like hybrid nature, high surface area, uniform porosity and chemical stability. ${ }^{8,9}$ Additionally, their tunability allows the integration of diverse functionalities such as redox centers in their structure using strategically predesigned organic linkers, with the targeted functionality. ${ }^{10-12}$ Organic redox center-based pseudocapacitors are known in polymeric materials; however, they exhibit low performance due to their low surface area and absence of uniform porosity. ${ }^{13,14}$

Recently, a few studies reported the application of MOFs and covalent-organic frameworks (COFs) as supercapacitor electrodes. Dincă et al. reported a 2-periodic conducting MOF-based supercapacitor having a $0.018 \mathrm{mF} \mathrm{cm}^{-2}$ capacitance. ${ }^{15}$ Yaghi et al. reported a series of MOFs, where $n \mathrm{MOF}-867$ had a maximum capacitance of $5.09 \mathrm{mF} \mathrm{cm}{ }^{-2}{ }^{16}$ Dichtel et al. reported a 2-periodic COF with an organic redox core having a capacity of $3 \mathrm{mF} \mathrm{cm}{ }^{-2} \cdot{ }^{11}$ Wang et al. reported ZIF-8 with a capacitance of $1.48 \mathrm{mF} \mathrm{cm}{ }^{-2} \cdot{ }^{17}$ However, less effort was dedicated to designing MOFs with redox active centers that can be specifically used for this application. ${ }^{18-21}$

Here we report the design and synthesis of a series of MOFs, by strategically incorporating a redox core in the organic linker and judiciously choosing a metal node to construct a porous and stable 3-periodic MOF (Fig. 1a). The $N, N^{\prime}$-bis(terphenyl-4,4"-di-carboxylic acid)naphthalenediimide $\left(\mathrm{H}_{4} \mathrm{BTD}-\mathrm{NDI}\right)$ linker with the NDI redoxactive center (Fig. S1-S6, ESI $\dagger$ ), which is known to have two characteristic electron redox processes was synthesized (Fig. 1b). ${ }^{22,23}$ It is important to notice that the requirement of long cycle life for the supercapacitor performance necessitates the use of a material combining both large porosity and high chemical and structural stability. ${ }^{24}$ Accordingly, we chose the $\left[\mathrm{Zr}_{6} \mathrm{O}_{8}\left(\mathrm{H}_{2} \mathrm{O}\right)_{8}\right]^{8+}$ cluster as a metal node to generate the targeted 3-periodic MOF porous structure with the aforesaid features. The requirement in terms of surface area is expected to increase the EDLC, while the porosity is expected to facilitate rapid ion transport through the MOF channels (Fig. 1a).

The optimized synthetic conditions (see the ESI $†$ Section S2) led to the synthesis of a needle shape like single crystal of the Zr-NDI-scu-MOF. The single crystal X-ray diffraction study shows that Zr-NDI-scu-MOF crystallizes in the orthorhombic 


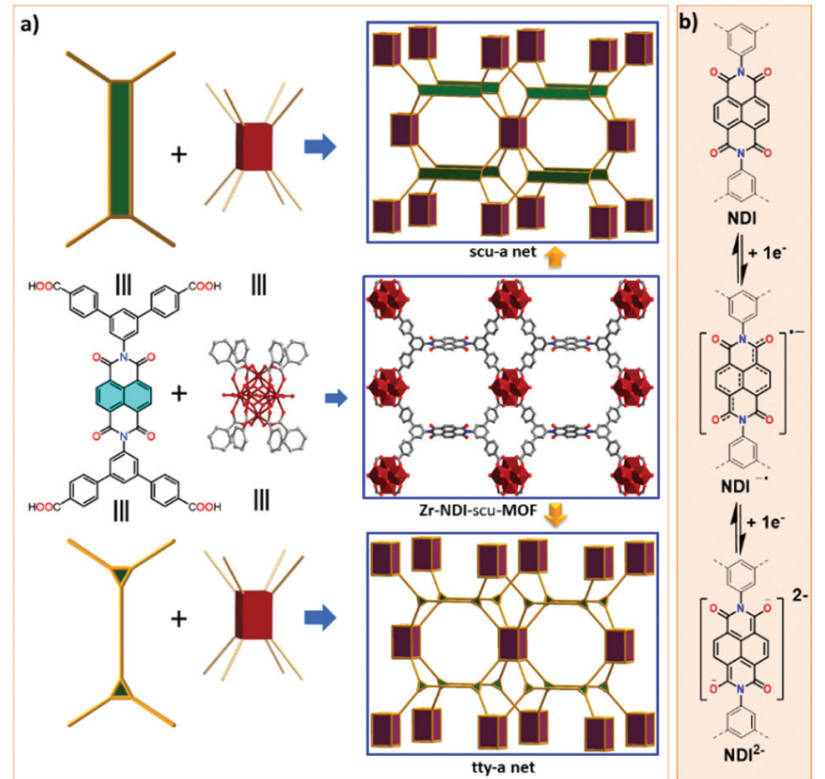

Fig. 1 (a) Schematic representation for the synthesis of Zr-NDI-scu-MOF and the different derived topologies. (b) The NDI core in the linker with the two electron redox process.

Cmmm space group with a formula unit of $\left[\mathrm{Zr}_{6} \mathrm{O}_{8}(\mathrm{BTD}-\mathrm{NDI})_{2}\right] \cdot x$ (solv) and cell parameters of $a=20.7974(9) \AA ; \quad b=34.320(1) \AA$ and $c=$ 24.2844(9) Å (Table S1, ESI $\dagger$ ). Zr-NDI-scu-MOF possesses a neutral framework with octahedral $\left[\mathrm{Zr}_{6} \mathrm{O}_{8}\left(\mathrm{H}_{2} \mathrm{O}\right)_{8}\right]^{8+}$ clusters, ${ }^{25}$ bridged by eight BTD-NDI ligands, leaving four pairs of terminal $\mathrm{H}_{2} \mathrm{O}$ groups at the equatorial plane suitable for further modification (Fig. 1 and Fig. S7, S8, ESI $\dagger$ ). The crystal structure analysis pinpoints to the presence of four types of interconnected channels. Two of them are parallel to the crystallographic $a$-axis and restricted by the apertures of 10.8 and $5.0 \AA$ formed by opposite pairs of NDI and extended isophthalic moieties, respectively (Fig. S8b, ESI $\dagger$ ). The channel with the smallest aperture of $2.7 \AA$ (distance between the NDI cores) is parallel to the crystallographic $b$-axis (Fig. S8c, ESI $\dagger$ ). Finally, the channel width parallel to the crystallographic direction $c$ is restricted by water molecules coordinated by two opposite $\mathrm{Zr}_{6}$-clusters with a water $\cdots$ water distance of $10.3 \AA$ (Fig. S8d, ESI $\dagger$ ). The NDI cores are arranged parallel to the last channel direction, which favors faster diffusion of incoming guest molecules. ${ }^{26}$ Fig. 1 displays the MOF topological analysis of the 8-connected hexanuclear $\mathrm{Zr}$ (Iv) molecular building block, that can be viewed as a cubic secondary building unit (SBU), while the organic ligand can be rationalized as a 4-connected building unit to give a $(4,8)-c$ scu-a net or can be viewed as a 3-c SBU resulting in a $(3,8)$-c derived tty-a net. ${ }^{27,28}$

The phase purity of Zr-NDI-scu-MOF was confirmed by matching the experimental powder X-ray diffraction (PXRD) pattern with that calculated from the crystal structure (Fig. S9, ESI $\dagger$ ). Interestingly, we observed a phase change from the PXRD pattern upon activation or solvent exchange (Fig. S10, ESI $\dagger$ ), with a clear shift of the PXRD peak from 4.7 to $5.1^{\circ}$. This shift is due to the flexibility of the framework upon solvent removal, which was further confirmed by variable temperature PXRD (VT-PXRD) (Fig. S11, ESI $\dagger$ ). The permanent porosity of Zr-NDI-scu-MOF was confirmed by the porosity analysis from the Ar sorption isotherm measured at $87 \mathrm{~K}$ (Fig. S12a, ESI $\dagger$ ). Zr-NDIscu-MOF shows a surface area of $810 \mathrm{~m}^{2} \mathrm{~g}^{-1}$; however the framework does not show the optimum pore volume compared to the calculated one (ESI, $\dagger$ Section S8), which could be due to the flexible nature of Zr-NDI-scu-MOF.

The electrochemical measurements on Zr-NDI-scu-MOF were performed using a three-electrode configuration in a $1 \mathrm{M} \mathrm{H}_{2} \mathrm{SO}_{4}$ electrolyte. The working electrode was prepared by drop-casting Zr-NDI-scu-MOF, carbon black, and polyvinylidene fluoride binder (8:1:1 weight ratio) mixture onto a carbon cloth electrode (the typical mass loading is $1.5-2 \mathrm{mg} \mathrm{cm}^{-2}$ ). These electrochemical measurements were performed using a $\mathrm{Ag} / \mathrm{AgCl}$ electrode and a Pt wire, which were used as the reference and the counter electrode, respectively. Fig. 2a shows the cyclic voltammetry (CV) curve for Zr-NDI-scu-MOF collected at a scan rate of $50 \mathrm{mV} \mathrm{s}^{-1}$. Owing to the $\mathrm{Zr}$-NDI-scu-MOF high surface area, an EDLC dominated behavior was observed, resulting from the adsorption of ions during the electrochemical process. Moreover, the NDI-core within $\mathrm{Zr}$-NDI-scu-MOF undergoes a reversible redox process, which is demonstrated by the exhibited well-defined electrochemical response. ${ }^{19}$ The CV curve exhibits a quasi-rectangular shape with distinct redox peaks, indicative of typical hybrid capacitive behavior. ${ }^{16,17}$ In particular, two anodic peaks located at around 0.4 and $0.6 \mathrm{~V} v$ s. Ag/AgCl (Fig. S13a, $\mathrm{ESI} \dagger$ ) are observed, corresponding to the two-step redox reaction for the NDI-core (Fig. 1b). ${ }^{17}$ The nonlinear galvanostatic charge-discharge (GCD) profile further suggests the occurrence of a faradaic process (Fig. 2b). Overall, the combination of EDLC and pseudocapacitive behavior was perceived. The capacitance calculated from the CV curves of Zr-NDI-scu-MOF electrode showed a capacitance of $16.8 \mathrm{~F} \mathrm{~g}^{-1}$ at a scan rate of $10 \mathrm{mV} \mathrm{s}^{-1}$.

An interesting feature of the Zr-NDI-scu-MOF structure is the flexible behavior (as attested by PXRD studies; Fig. S9 and S10, $\mathrm{ESI} \dagger$ ) driven by the removal/uptake of solvent, which could affect its performance as a supercapacitor electrode, as a result of surface area variation. ${ }^{26}$ Therefore we explored an alternative strategy to enhance the rigidity of the MOF structure, which will help in maintaining the open structure and the optimal/fixed surface area.
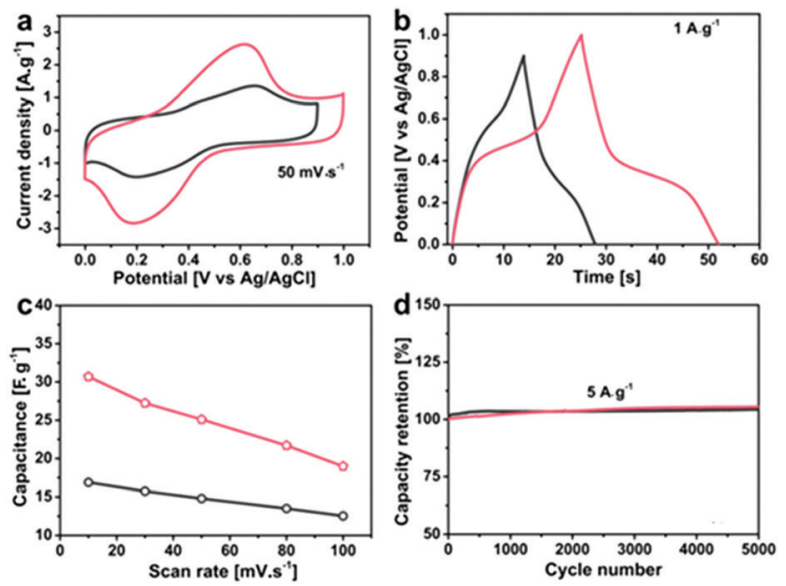

Fig. 2 (a) Zr-NDI-scu-MOF (red) and Zr-NDI-BPy-sco-MOF (black) electrodes tested as supercapacitors in $1 \mathrm{M} \mathrm{H}_{2} \mathrm{SO}_{4}$. (b) $\mathrm{CV}$ curves collected at $50 \mathrm{mV} \mathrm{s}^{-1}$, (c) GCD profiles at $1 \mathrm{~A} \mathrm{~g}^{-1}$ capacity, and (d) stability tests performed at $5 \mathrm{~A} \mathrm{~g}^{-1}$. 
A careful examination of the Zr-NDI-scu-MOF crystal structure shows that the windows of the channels parallel to the $c$-axis are formed by four $\mathrm{Zr}$-clusters and four extended isophthalic moieties of the ligands. Such ligand coordination allows the MOF flexibility via changing the angles between carboxylates and Zr-clusters towards more deformed rhombic or the perfect square windows; elongation or shortening of the unit cell parameters $a$ and $b$; shown in Fig. 3. Since each window lying outside the $a b$-plane is formed by two Zr-clusters and two ligands, any MOF deformation demands a ligand shape change, which in this case is much less labile than the Zr-coordination sphere. As a result of the framework flexibility, a partial rupture of the framework occurs upon solvent removal. Additionally, each $\mathrm{Zr}$ cluster contains eight water molecules, with four molecules facing the $a$-axis and the other four along the $c$-axis (Fig. 3). Therefore these open sites offer the opportunity to install another linker by replacing the water molecules and linking the Zr-clusters along the $a$-axis. Thus the flexible $\mathrm{Zr}-\mathrm{NDI}-\mathrm{scu}-\mathrm{MOF}$ can be transformed into a more rigid Zr-NDI-BPy-sco-MOF via this strategy (Fig. 3 and Fig. S14, ESI $\dagger$ ). ${ }^{29,30}$

The post-synthetic linker installation was carried out using a 2,2'-bipyridine-5, $5^{\prime}$-dicarboxylic acid (BPy) organic linker as the pillar as described in the ESI, $\dagger$ since the distance between the two opposite water molecules along the $a$-axis is about $12.36 \AA$, which allows the BPy ligand of $11.1 \AA$ Alength to be accommodated. Also, it is worth mentioning that it has been reported that the $\mathrm{sp}^{2}$ nitrogen has effective interaction with the electrolyte and thus enhances the capacity. ${ }^{16}$ The amount of linker installed was estimated by means of nuclear magnetic resonance (NMR) studies on the digested MOF in $\mathrm{HCl}$, which was found to be $85 \%$ of the available binding sites (Fig. S15, ESI $\dagger$ ). The post-installation of the linkers was also confirmed by PXRD, Infrared spectroscopy (IR), thermal gravimetrical analysis (TGA), elemental analysis, and surface area analysis (Fig. S16-S18 and S12b, $\mathrm{ESI} \dagger$ ). The obtained Zr-NDI-BPy-sco-MOF was fully characterized using PXRD (Fig. S16, ESI $\dagger$ ), which showed that the framework maintained its crystallinity and proved the formation of the expected geometry optimized structure that was simulated using materials studio software (more details about the employed simulation method are described in the ESI $\dagger) .{ }^{31}$ The experimental PXRD has an excellent matching with the simulated pattern of the Zr-NDI-BPy-sco-MOF (Fig. S16, ESI $\dagger$ ) Additionally, Ar sorption measurement showed about two-fold

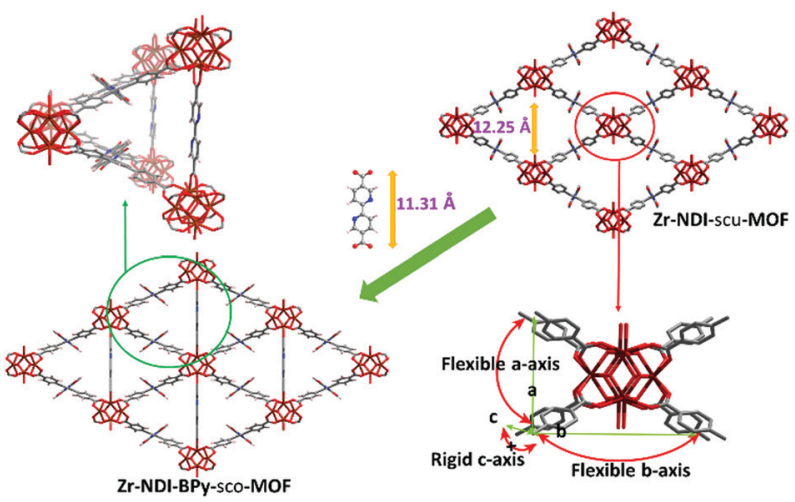

Fig. 3 Schematic representation of the synthesis of $\mathrm{Zr}-\mathrm{NDI}-\mathrm{BPy}$-scoMOF via insertion of the 2,2' - bipyridine-5, $5^{\prime}$-dicarboxylic acid (BPy) pillar along the a-axes of $\mathrm{Zr}-\mathrm{NDI}-\mathbf{s c u}-\mathrm{MOF}$. enhancement in the surface area $\left(1820 \mathrm{~m}^{2} \mathrm{~g}^{-1}\right)$ of Zr-NDI-BPy-scoMOF with respect to Zr-NDI-scu-MOF $\left(810 \mathrm{~m}^{2} \mathrm{~g}^{-1}\right)$ (Fig. S12b, ESI $\dagger$ ). A narrowing of the average pore size with a much higher degree of uniformity after post-installation of the BPy linker was observed (inset in Fig. S12b, ESI $\dagger$ ), supporting the formation of a relatively more rigid structure.

The increase in the surface area is expected to further boost the supercapacitor performance, ${ }^{32}$ and indeed, the $\mathrm{CV}$ area of the Zr-NDI-BPy-sco-MOF (Fig. 2a) has significantly increased as compared to that of Zr-NDI-scu-MOF. Note that for both MOFs, the CV curves show similar shapes and redox peaks (Fig. S13b, ESI $\dagger$ ). The storage mechanism of Zr-NDI-scu-MOF and Zr-NDI-BPy-sco-MOF materials was determined by the $b$-values, which can be obtained by plotting the peak current against scan rate (see Methods in the ESI $\dagger$ ). For both MOFs, the $b$-values are within 0.5-0.8 (Fig. S19, ESI $\dagger$ ), which implies that the charge storage is mostly dominated by the diffusion controlled process. These results suggest that the capacitance can be greatly enhanced by decreasing the flexibility of the structure by simply installing the BPy linker. The GCD curve again confirms this enhancement (Fig. 2b) and the calculated capacitance of Zr-NDI-BPy-sco-MOF was $30.75 \mathrm{~F} \mathrm{~g}^{-1}$ (Fig. 2c), i.e. twice that of Zr-NDI-scu-MOF, which is in good agreement with the enhancement in the surface area. On the other hand, the potential window could be extended to $1.0 \mathrm{~V}$ (Fig. 2a and Fig. S20, ESI $\dagger$ ), which indicates that the oxygen evolution reaction on Zr-NDI-BPy-sco-MOF was restricted to some degree. ${ }^{20}$ Such widened potential window is preferred as it can improve the energy and power density of the devices. ${ }^{33}$ The pronounced potential plateaus observed in the GCD profile (Fig. 2b) are related to the faradaic reactions of the NDI core, which is in agreement with the CV measurements. These results further confirm the efficacy of our strategy by rigidifying the MOF structure to boost the electrochemical performance.

The two types of MOFs were highly stable during CV measurements in $1 \mathrm{M} \mathrm{H}_{2} \mathrm{SO}_{4}$ (Fig. 2d), and did not show a significant decay for at least 5000 cycles even under a relatively high current density $\left(5 \mathrm{~A} \mathrm{~g}^{-1}\right)$. Encouraged by these promising results, the best performing Zr-NDIBPy-sco-MOF was further investigated by constructing a symmetrical two-electrode device using two nearly identical electrodes from this MOF and graphite. ${ }^{35}$ The preparation of the MOF on graphite electrodes was carried out in the same way as in the 3-electrode measurements and they were used as the positive and negative electrodes, respectively. The electrolyte used in these measurements was $1 \mathrm{M}$ $\mathrm{H}_{2} \mathrm{SO}_{4}$ and based on the three electrode measurements, these devices were tested in a voltage window of 0-1.0 V. Fig. 4a shows the typical CVs collected at different scan rates, which exhibit a quasi-rectangular mirror-symmetric shape even at high scan rates (e.g. $200 \mathrm{mV} \mathrm{s}^{-1}$ ), indicating the highly reversible charge/discharge response of the device. $^{34,35}$ The triangular symmetric GCD curves are shown in Fig. $4 \mathrm{~b}$ and indicate a high coulombic efficiency. The cell capacitance was calculated based on the $\mathrm{CV}$ curves and the device can deliver a capacitance of $5.7 \mathrm{~F} \mathrm{~g}^{-1}$ at $10 \mathrm{mV} \mathrm{s}^{-1}$. Fig. 4 shows the cycling stability of our Zr-NDI-BPy-sco-MOF devices in $1 \mathrm{M} \mathrm{H}_{2} \mathrm{SO}_{4}$ for up to 10000 cycles. These MOF-based devices showed the capacity retention of $99.9 \%$ after $10 \mathrm{~K}$ cycles, while most of the reported MOF-based supercapacitors retain less than $80 \%$ of the initial capacitance after $10 \mathrm{~K}$ cycles. ${ }^{30}$ This is due to enhanced structure rigidity, which hinders the structural collapse during the charge/discharge process. The XRD 

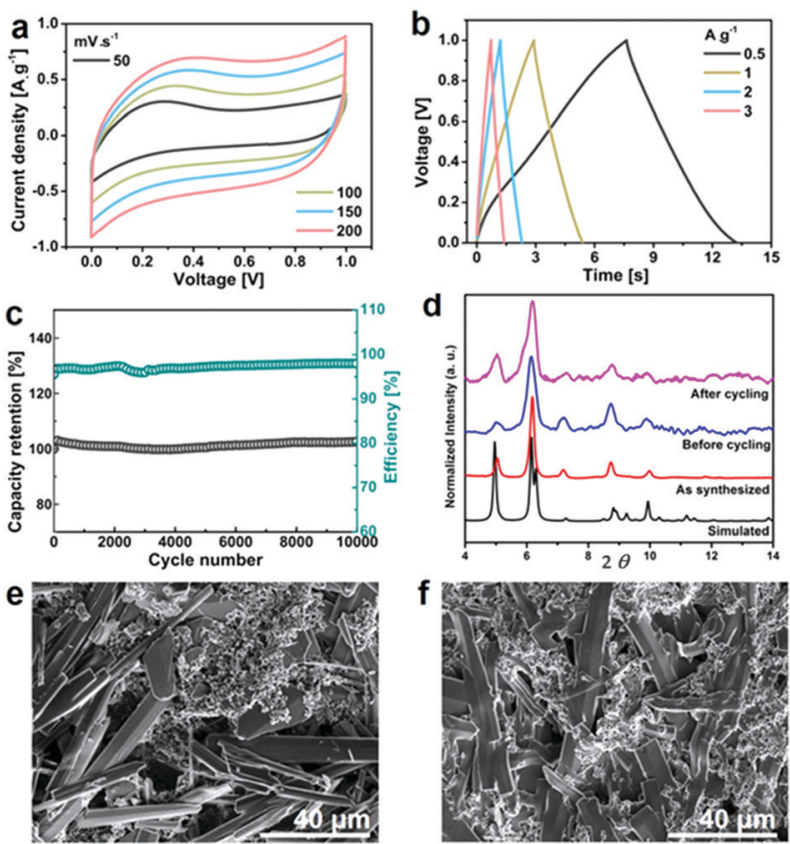

Fig. 4 (a) CV curves measured at different scan rates for Zr-NDI-BPy-scoMOF symmetric devices. (b) GCD curve measured at different current densities for Zr-NDI-BPy-sco-MOF. (c) Cyclic stability performed at $2 \mathrm{~A} \mathrm{~g}^{-1}$ up to 10000 cycles for Zr-NDI-scu-MOF (black) and Zr-NDI-BPy-sco-MOF (blue). (d) PXRD pattern before and after the electrochemical measurements for Zr-NDI-BPy-sco-MOF. SEM images for the Zr-NDI-BPy-sco-MOF electrode before (e) and after ( $f$ ) electrochemical measurements.

and SEM characterization of the electrodes before and after $10 \mathrm{~K}$ cycles of charge/discharge process (Fig. 4d-f and Fig. S20, ESI $\dagger$ ) shows no significant changes in the PXRD or crystal morphology. Notably, we achieved an areal capacitance of $5.48 \mathrm{mF} \mathrm{cm}^{-2}$ in aqueous medium with a voltage window of $0.0-1.0 \mathrm{~V}$, which is higher than most of the reported values achieved in much more expensive organic electrolytes for MOF materials (see Table S2, ESI $\dagger$ ), where areal capacitance was used for comparison with other MOFs reported in the literature. ${ }^{36,37}$ The energy density and the power density were further examined for the Zr-NDI-BPy-sco-MOF, which was found to be able to deliver an energy density of $472 \mathrm{~mW} \mathrm{~h} \mathrm{~kg}^{-1}$ at a power density of $250 \mathrm{~W} \mathrm{~kg}^{-1}$, which is one of the best performing among the 3D MOF-based supercapacitor materials.

In conclusion, we have successfully synthesized a 3-periodic Zr-based MOF, namely Zr-NDI-scu-MOF, having an organic linker with a redox active core. This newly developed platform possesses tunable and high surface area combined with a redox active core. It can be applied as a supercapacitor electrode, that provides both EDLC and pseudocapacitance. The post-synthetic modification of the pristine structure by BPy resulted in Zr-NDI-BPy-sco-MOF increased rigidity and enhanced surface area, and improved its capacitance performance (by a factor of 2 ). This work reveals a new rational strategy for designing made-to-order MOFs for capacitive energy storage applications. Work is in progress to extend this application into micro-supercapacitor devices.

This work was financially supported by the King Abdullah University of Science and Technology (KAUST) under Award No. OSR-CRG2017-3379.

\section{Conflicts of interest}

There are no conflicts to declare.

\section{Notes and references}

1 M. Winter and R. Brodd, Chem. Rev., 2004, 104, 4245-4269.

2 P. G. Bruce, Solid State Ionics, 2008, 179, 752-760.

3 D. Larcher and J. M. Tarascon, Nat. Chem., 2014, 7, 19-29.

4 F. Béguin and E. Frackowiak, Supercapacitors: Materials, Systems, and Applications, Wiley-VCH, 2013.

5 G. Z. Chen, Int. Mater. Rev., 2016, 62, 173-202.

6 J. Chmiola, C. Largeot, P.-L. Taberna, P. Simon and Y. Gogotsi, Science, 2010, 328, 480-483.

7 M. F. El-Kady, V. Strong, S. Dubin and R. B. Kaner, Science, 2012, 335, 1326-1330.

8 G. Ferey, Chem. Soc. Rev., 2008, 37, 191-214.

9 H. C. Zhou, J. R. Long and O. M. Yaghi, Chem. Rev., 2012, 112, 673-674.

10 S. Chandra, D. Roy Chowdhury, M. Addicoat, T. Heine, A. Paul and R. Banerjee, Chem. Mater., 2017, 29, 2074-2080.

11 C. R. DeBlase, K. Hernández-Burgos, K. E. Silberstein, G. G. RodrfíguezCalero, R. P. Bisbey, H. D. Abruna and W. R. Dichtel, ACS Nano, 2015, 9, 3178-3183.

12 Y. Xu, Z. Lin, X. Huang, Y. Wang, Y. Huang and X. Duan, Adv. Mater., 2013, 25, 5779.

13 D. F. Zeigler, S. L. Candelaria, K. A. Mazzio, T. R. Martin, E. Uchaker, S.-L. Suraru, L. J. Kang, G. Cao and C. K. Luscombe, Macromolecules, 2015, 48, 5196-5203.

14 M. Sun, Q. Tang, T. Zhang and G. Wang, RSC Adv., 2014, 4, 7774-7779.

15 D. Sheberla, J. C. Bachman, J. S. Elias, C.-J. Sun, Y. Shao-Horn and M. Dinca, Nat. Mater., 2017, 16, 220-224.

16 K. M. Choi, H. M. Jeong, J. H. Park, Y.-B. Zhang, J. K. Kang and O. M. Yaghi, ACS Nano, 2014, 8, 7451-7457.

17 L. Wang, X. Feng, L. Ren, Q. Piao, J. Zhong, Y. Wang, H. Li, Y. Chen and B. Wang, J. Am. Chem. Soc., 2015, 137, 4920-4923.

18 J. Calbo, M. J. Golomb and A. Walsh, J. Mater. Chem. A, 2019, 7, 16571-16597.

19 D. M. D'Alessandro, Chem. Commun., 2016, 52, 8957-8971.

20 G. Zhu, H. Wen, M. Ma, W. Wang, L. Yang, L. Wang, X. Shi, X. Cheng, X. Sun and Y. Yao, Chem. Commun., 2018, 54, 10499-10502.

21 S. Sundriyal, H. Kaur, S. K. Bhardwaj, S. Mishra, K.-H. Kim and A. Deep, Coord. Chem. Rev., 2018, 369, 15-38.

22 Z. Song, H. Zhan and Y. Zhou, Angew. Chem., Int. Ed., 2010, 49, 8444-8448.

23 D. Chen, A.-J. Avestro, Z. Chen, J. Sun, S. Wang, M. Xiao, Z. Erno, M. M. Algaradah, M. S. Nassar, K. Amine, Y. Meng and J. F. Stoddart, Adv. Mater., 2015, 27, 2907-2912.

24 P. Deria, D. A. Gómez-Gualdrón, I. Hod, R. Q. Snurr, J. T. Hupp and O. K. Farha, J. Am. Chem. Soc., 2016, 138, 14449-14457.

25 J. Lyu, X. Zhang, P. Li, X. Wang, C. T. Buru, P. Bai, X. Guo and O. K. Farha, Chem. Mater., 2019, 31(11), 4166-4172.

26 N. C. Thacker, Z. Lin, T. Zhang, J. C. Gilhula, C. W. Abney and W. Lin, J. Am. Chem. Soc., 2016, 138, 3501-3509.

27 O. Delgado-Friedrichs, M. O'Keeffea and O. M. Yaghi, Acta Crystallogr., Sect. A: Found. Crystallogr., 2006, 62, 350-355.

28 V. Guillerm, D. Kim, J. F. Eubank, R. Luebke, X. Liu, K. Adil, M. S. Lah and M. Eddaoudi, Chem. Soc. Rev., 2014, 43, 6141-6172.

29 C.-X. Chen, Z.-W. Wei, J.-J. Jiang, S.-P. Zheng, H.-P. Wang, Q.-F. Qiu, C.-C. Cao, D. Fenske and C.-Y. Su, J. Am. Chem. Soc., 2017, 139, 6034-6037.

30 S. Yuan, Y.-P. Chen, J.-S. Qin, W. Lu, L. Zou, Q. Zhang, X. Wang, X. Sun and H.-C. Zhou, J. Am. Chem. Soc., 2016, 138, 8912-8919.

31 Materials Studio 7.0, Accelrys Software Inc., San Diego, CA 92121, USA.

32 H. Wang, T. Maiyalagan and X. Wang, ACS Catal., 2012, 2, 781-794.

33 H. M. Jeong, J. W. Lee, W. H. Shin, Y. J. Choi, H. J. Shin, J. K. Kang and J. W. Choi, Nano Lett., 2011, 11, 2472-2477.

34 H. Ji, X. Zhao, Z. Qiao, J. Jung, Y. Zhu, Y. Lu, L. L. Zhang, A. H. Mac-Donald and R. S. Ruoff, Nat. Commun., 2014, 5, 3317.

35 C. Largeot, C. Portet, J. Chmiola, P. L. Taberna, Y. Gogotsi and P. Simon, J. Am. Chem. Soc., 2008, 130, 2730-2731.

36 L. Wang, Y. Han, X. Feng, J. Zhou, P. Qi and B. Wang, Coord. Chem. Rev., 2016, 307, 361-381.

37 W. Chen, R. B. Rakhi, L. Hu, X. Xie, Y. Cui and H. N. Alshareef, Nano Lett., 2011, 11, 5165-5172. 